\title{
The contribution of foreign real estate investment to housing price growth in Australian capital cities
}

\author{
Ross Guest \\ Nicholas Rohde \\ Department of Accounting, Finance and Economics \\ Griffith University
}

\begin{abstract}
This paper models the effects of foreign investment in real estate on housing prices in Australia. We use a variety of panel data models that account for cross-sectional heterogeneity across Australian cities and find that increases in investment are significant predictors of rises in the Australian Bureau of Statistics' Residential Property Price Index. Our results are generally robust and suggest that increases in foreign investment account for between $20 \%$ and $30 \%$ of the rise in housing prices between 2004 and 2014 in Sydney and Melbourne. In other capital cities the effects appear to be negligible. Some policy implications of our findings are discussed.
\end{abstract}

Key Words: foreign investment, real estate, housing prices.

JEL Classification: R30, R31, R38 


\section{Introduction}

Over 2004-2014 house prices rose across Sydney and Melbourne by an average of 64\% while at the same time proposed foreign investment in developed residential real estate rose by almost tenfold. This rate of house price has considerably out-paced that in most OECD countries over the same period. Some corresponding figures are: U.S 7\%, U.K. 27\%, Germany 17\%, Japan -23\%, S. Korea 39\% and the global average 14\% (Federal Reserve Bank of Dallas, 2016).

The deteriorating housing affordability in Sydney and Melbourne and the apparent surge in foreign residential real estate investment led to a Parliamentary Inquiry into this subject. The Report (Commonwealth of Australia, 2014) found, first, that there is little accurate data on foreign investment in Australian residential real estate and therefore "no-one really knows how much foreign investment there is in residential real estate” (page iv). Second, the accounting and reporting arrangements for foreign real estate investment have not allowed any court action by the Foreign Investment Review Board (FIRB) since 2006 in relation to foreign real estate investment. The Report recommended better audit, compliance and enforcement processes at the FIRB, along with harsher penalties for transgressions related to the value of the property purchased.

Despite the apparent correlation between housing price growth and foreign real estate investment in Sydney and Melbourne in recent years, the relationship is complicated by a number of factors apart from the paucity of data. Gauder et al. (2014) point out that an increase in foreign real estate investment does not necessarily imply a net increase in housing demand and therefore upward pressure on housing prices. For example, if the dwelling is purchased and then rented out to someone who is already in the housing market, including a non-citizen child studying in Australia, then the purchase itself does not add to the demand for housing. Gauder et al. (2014) also note that foreign buyers may subsequently become foreign sellers, hence the net impact on the housing market depends on whether the flow of purchases is greater than the flow of sales by foreign citizens. And housing purchases by nonpermanent residents who subsequently become permanent residents represents a shifting forward of housing demand - the demand increases but it is due to an increase in population which is regarded as a fundamental driver of housing demand rather than due to foreign investment.

Further, growth in average house prices does not equate exactly to a change in housing affordability for first home buyers. Gauder et al. (2014) report evidence that first home buyers have generally purchased the cheaper and established dwellings rather than new dwellings, both of which are housing categories where foreign investment is less evident. In any case, other work by the Reserve Bank of Australia in Kohler et al. (2015) finds that house price growth over the past 30 years can be largely explained by fundamental factors such as financial deregulation, the ability of housing supply to respond to demand, and population growth driven by immigration. This suggests that foreign direct investment may play a relatively minor role in explaining house price growth. 
The above research tends to downplay the role of foreign real estate investment in driving housing prices and housing affordability. However, it is unresolved and remains a significant issue in the media, through anecdotal stories of Chinese buyers fuelling Sydney housing prices (SMH, 2014). Such media reports claim that foreign buyers are flouting laws prohibiting non-resident buyers from purchasing existing homes, and requiring temporary residents, who are allowed to purchase one existing home as their primary residence, to sell their homes once their visa expires.

Hence there is sufficient uncertainty and controversy about the data to warrant further econometric analysis which is the purpose of this study. In particular the aim is to analyse the available data set on foreign real estate investment and housing prices in Australian capital cities to determine the contribution of foreign real estate investment to house price growth.

\section{Data}

We assemble a unique data set on real estate prices and foreign investment by combining Australian Bureau of Statistics (ABS) data with information from the Foreign Investment Review Board (FIRB). Housing prices are measured using the Residential Property Price Index (RPPI) generated by the ABS for Australia's eight capital cities. As its name suggests, the index quantifies property price changes where the primary role of the dwelling is residential ${ }^{1}$ (and hence all non-residential property is excluded). The data is reported on a quarterly basis, however based on the frequency of our other series we take four period averages to produce annual estimates. Given that the RPPI is generally quoted in nominal terms we do not re-standardize relative to a base year and employ raw values throughout. Foreign investment is proxied by proposed investment in real estate by state or territory provided by FIRB in its annual reports and is denominated in billions of current value dollars. This investment is proposed which may of course not be the same as actual, and it is measured at a broader geographical level than our housing price data. However, we assume that it is representative of realized purchases in the relevant capital city. Thus the investment data is best interpreted as an approximate indicator rather than as a precise economic measurement, which places some caveats upon our results. ${ }^{2}$ Importantly the foreign investment data is able to be stratified into "Developed" real estate and land "For Development" which allows our models to differentiate between the effects of these types of purchases on housing prices. Developed real estate primarily consists of planned purchases by temporary residents in housing while the "For Development" category is made up of several subcategories including vacant land and property for redevelopment.

\footnotetext{
${ }^{1}$ This includes (i) detached houses, (ii) houses with offices or flats, (iii) rural residential houses, (iv) semidetached row and terrace houses, (iv) townhouses and (v) flats, units and apartments.

${ }^{2}$ If the covariates are measured with error then then regular statistical estimators such as OLS will no longer be consistent (Griliches, 1984) with the magnitude of the problem a function of the degree of error. Given that we have multiple covariates in our models we are unable to anticipate the direction of any bias. Various potential solutions to this problem exist such as the use of instrumental variable estimators, however implementation of these techniques is infeasible in our case. Thus our work depends quite strongly upon the assumption that the FIRB data forms a strong proxy for actual investment.
} 
In addition to these central variables of interest we also take annual data on population growth, labour earnings, consumer prices and unemployment. These variables control for variations in housing prices determined by factors that typically drive housing investment and prices other than foreign investment. For example growth in consumer prices generally may exert upward pressure on housing prices while cyclical factors related to aggregate demand (measured by the unemployment rate) may also have some influence. Again in some cases these are measured at the state rather than city level and hence we require assumptions about the representativeness of each.

The longest time span for which we are able to assemble a complete data set is from 20042014 and hence for each city we have a short (eleven year) time-series available. Although many of the other variables extend back farther than 2004 our investment data becomes sparse before this date, ruling out the possibility of producing a balanced data set. Given that it is unlikely that missing observations (such as due to a small population size in a state for observations in 2002 or 2003) would appear purely at random, our data would violate the Missing at Random (MaR) assumption if we did not truncate at 2004. As a consequence our time-series are far too short in isolation for us to be able to conduct meaningful econometric analysis $^{3}$ and therefore we merge them together to form a panel. This data set consists of eight cross sectional units and eleven waves and thus contains a fairly limited 88 observationyears in total. By assembling our data in this fashion we are able to exploit many of the advantages that panel techniques have over cross-sectional methods (such as an ability to control for individual-specific heterogeneity) and hence produce estimates that are much less susceptible to biases due to omitted variables.

Once the data are gathered we look to motivate our analysis by describing some of the apparent trends. Figures 1-4 show time-series plots of four primary variables of interest; the ABS residential property price index, the price level in all eight Australian capital cities and our measures of foreign investment in developed and undeveloped residential real estate.

\footnotetext{
${ }^{3}$ Otto (2007) was able to successfully estimate time-series models of Australian housing price indices however his data sets were considerably longer than ours.
} 


\section{Figure 1. ABS Residential Property Price Indices - Eight Capital Cities}

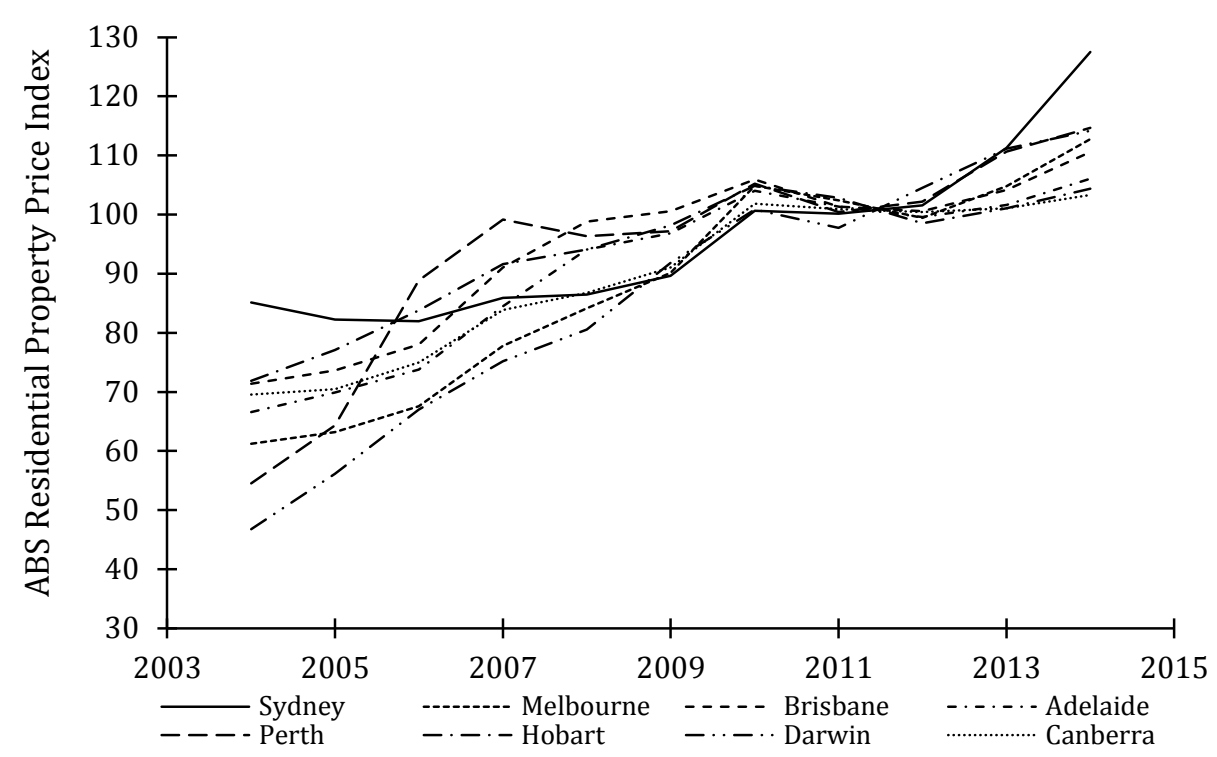

Note: The vertical axis gives the RPPI index recorded in each city while the horizontal axis gives the year. Data and details on construction of the variable can be found at the ABS website. See http://www.abs.gov.au/AUSSTATS/abs@.nsf/Lookup/6416.0 Explanatory\% 20Notes1 Jun\%202015.

The data depicted in Figure 1 shows the rise in residential property prices in Australian cities since 2004. In all cases there is a strong increasing trend with the spike in prices in Sydney from 2011 to 2014 being especially prominent. On average the index started around 62.9 in 2004 and was 111.7 in 2014 and hence a 78\% increase was observed over the eleven year period, averaging at a compounding rate of $5.4 \%$ per year. An important feature of Figure 1 is that there is considerable heterogeneity in trends across the eight cities. For example Perth experienced low but rapidly growing prices in the earlier part of the period but slow growth after 2007. Sydney prices had the reverse trend while prices in Melbourne grew steadily throughout.

The trends in Figure 1 can be placed in context by comparing them to the increases in consumer prices depicted in Figure 2. These indices grew from a value of approximately 79 in 2004 to 106 in 2014 and hence increased by approximately 35\% at an average rate of 2.75\% per year. Consequently we see that the RPPI has risen at approximately twice the rate of consumer prices over the last decade. More notable however is the fact that the growth trajectories were extremely stable and also similar across all eight cities. This implies that the heterogeneity in housing price growth (i) across cities, and (ii) over time, depicted in Figure 1 cannot be explained by broad differentials in inflation. Indeed we must look for some other reason why housing prices grew rapidly in some years for some cities and not for others. 
Figure 2. ABS Price Indices - Eight Capital Cities

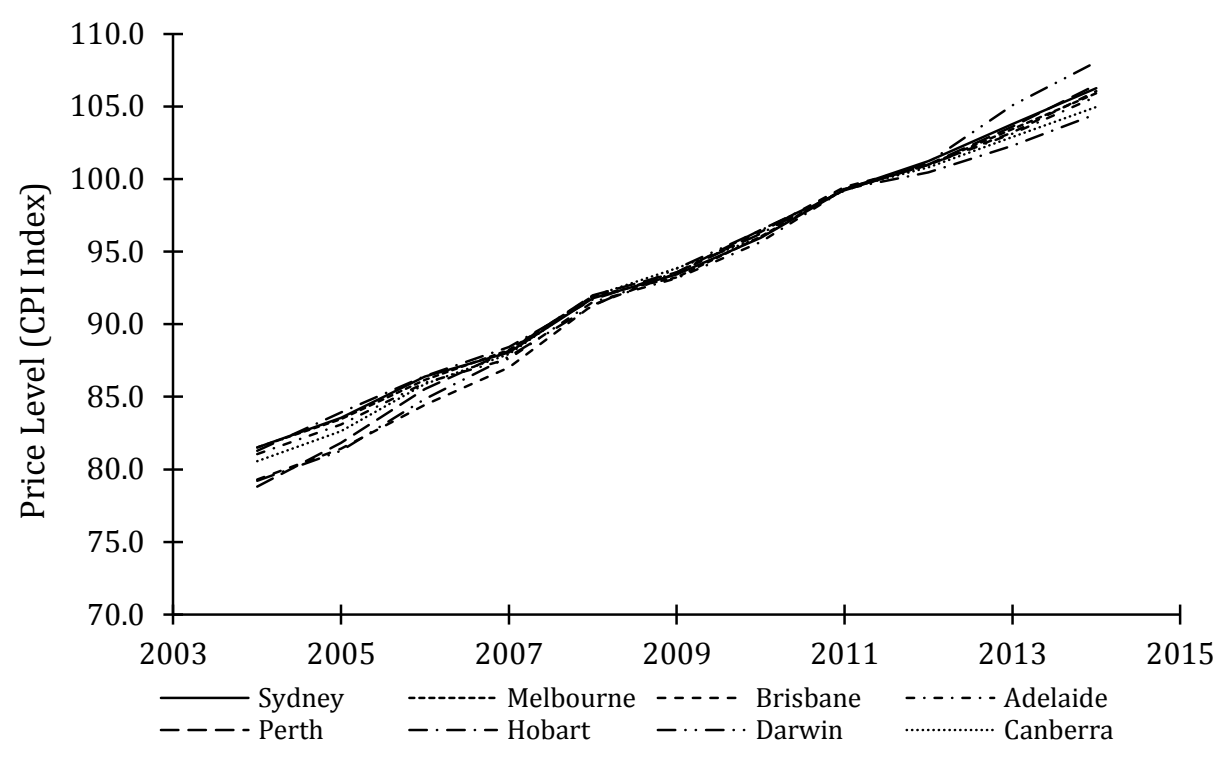

Note: The vertical axis gives the price index recorded in each city while the horizontal axis gives the year. See the ABS website for data and details on construction of this variable http://www.abs.gov.au/AUSSTATS/abs@.nsf/DetailsPage/6401.0Jun\%20205

Given that housing markets are plausibly sensitive to local factors and other economic conditions we hypothesize that once the contributions from other economic fundamentals are stripped away, some of the variation depicted in Figure 1 can be explained by differentials in foreign investment. To illustrate this case Figures 3 and 4 show proposed foreign investment in developed residential real estate and real estate for development. It can be seen that foreign investment in Australian real estate has been volatile for both developed and undeveloped land since 2004, although the volatility is especially pronounced in the latter case. However, despite this volatility investment was generally increasing over the period for most cities. Aside from a small downturn from 2008-2010 that is evident in both series, foreign investment generally rose in Australia, and in some instances this rise was quite dramatic. For example in New South Wales and Victoria, developed investment increased from less than \$0.5b in 2010 to \$3.6b and \$2.8b in 2014 respectively. It is worth noting that there are some general similarities between this plot and the price index data depicted in Figure 1; for example the dip in developed investment across all states in 2010 coincides with the beginning of a period of slower growth in housing prices in the major cities. Similarly when we turn to investment in property for development we also see surges for NSW and Victoria from 2010 onwards. Notably in Brisbane, where housing prices increased less rapidly, this form of investment actually fell over our time period. Thus again we see evidence of raw associations existing between our key variables of interest. 
Figure 3. Foreign Investment in Developed Residential Real Estate by State

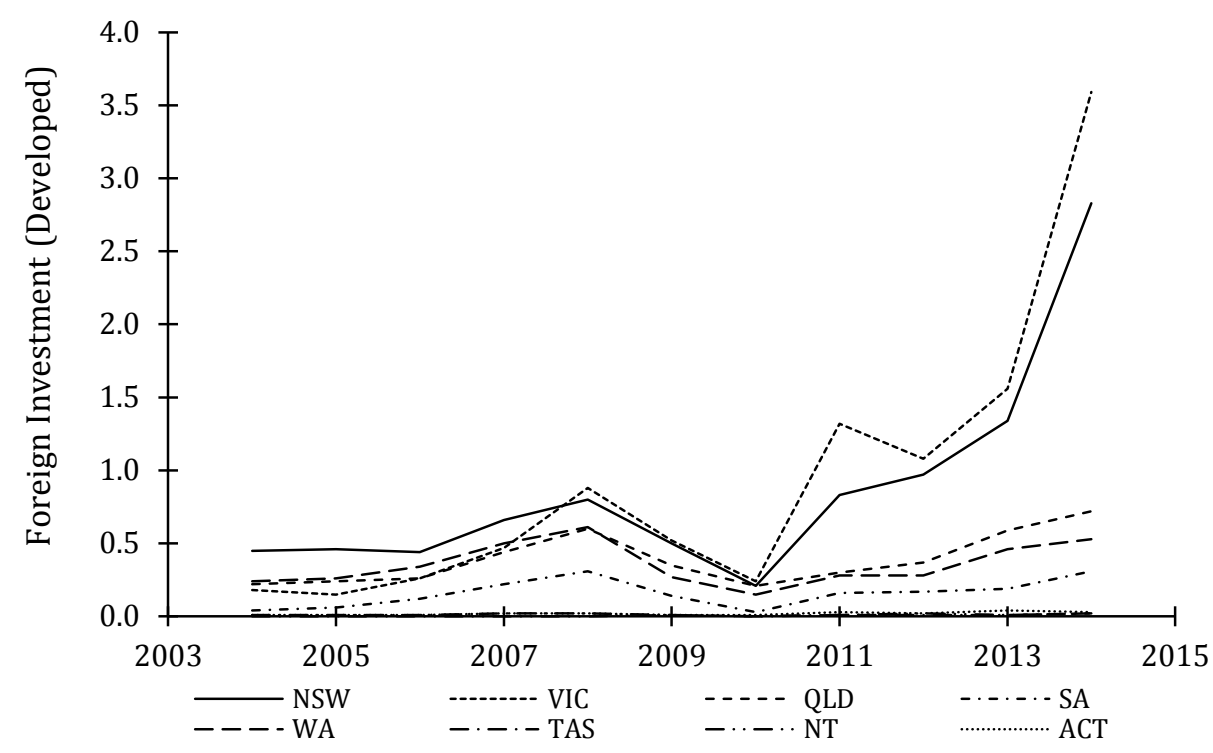

Note: The vertical axis gives the quantity of proposed investment in developed real estate in billions of dollars for each state while the horizontal axis gives the year. Information is taken from FIRB annual reports from 2004 to 2001. See http://www.firb.gov.au/content/publications.asp for details.

\section{Figure 4. Foreign Investment in Residential Real Estate for Development}

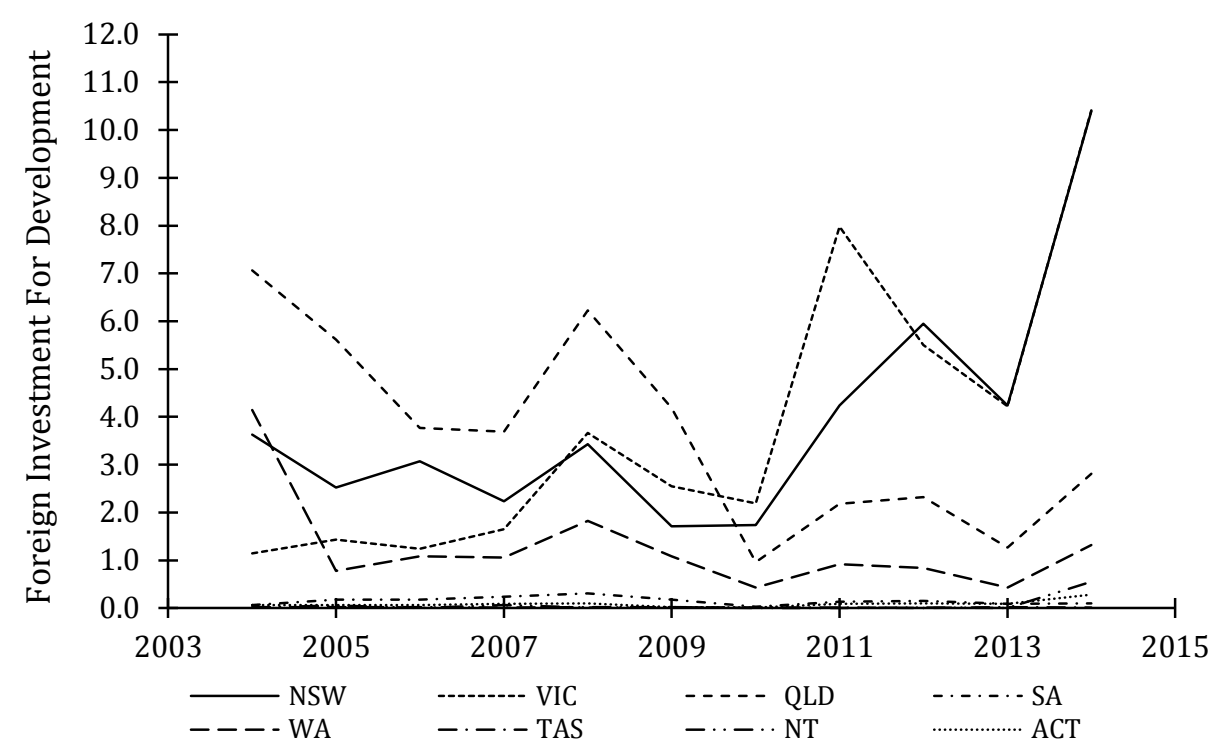

Note: The vertical axis gives the quantity of proposed investment in real estate for development in billions of dollars for each state while the horizontal axis gives the year. Information is taken from FIRB annual reports from 2004 to 2001. See http://www.firb.gov.au/content/publications.asp for details. 
Further analysis of the data depicted in Figures 1-4 suggests that strong serial correlation in a prominent feature of both prices and investment. The housing data in Figure 1 and the price index in Figure 2 are both depicted as smooth series where the value in a given time period is generally similar to that of the previous period. Although the investment data in Figures 3 and 4 are noisier they also exhibit this phenomenon. This suggests that the data may share an equilibrium (cointegating) relationship that may be exploited with an appropriate class of econometric models. Although such a relationship is a genuine possibility we regard our time-series component of 11 waves to be insufficient to verify the presence of integration and hence do not pursue this modelling strategy, but note that the technique will be accessible in the future as the available data set expands.

\section{Methods and Results}

Given the trends observed trends, we now look to model the effect of each type of investment upon our price index subject to the constraints imposed by the data. Although the time-series component is short, the combination with eight cross sections allows us to employ a basket of panel data models for this purpose each with their own specific advantages and disadvantages. Initially we apply fixed-effects and random effects models of the general form

$$
y_{i t}=\alpha+\gamma_{t}+\mathbf{x}_{i t}^{\prime} \boldsymbol{\beta}+u_{i}+\varepsilon_{i t}
$$

where $y_{i t}$ denotes the price index in city $i$ in period $t, \gamma_{t}$ represents a dummy accounting for year-specific effects at time $t, \alpha$ is a constant term, $u_{i}$ an individual-specific effect and $\varepsilon_{i t}$ is an error term. The main parameters of interest are represented by the $k$ dimensional vector $\boldsymbol{\beta}$ where $\mathbf{x}_{i t}^{\prime}$ is also a $k$ vector of covariates for observation $i$ at time $t$. Foreign investment is included here alongside a set of control variables that capture changes in economic and demographic conditions. The fixed-effects version of this model only employs within-type variation and hence allows for correlation between the $u_{i}$ terms and the $\mathbf{x}_{i t}^{\prime}$ terms. As a consequence this model is robust to misspecification issues related to time time-invariant heterogeneity. Conversely the random-effects model employs an optimal combination of within-type and between-type variation which allows for more precise parameter estimation, although this efficiency can come at the cost of endogeneity biases.

We fit both models to our data using three variations of the standard specification given in $\mathrm{EQ}(1)$. The full specification employs all available controls, however for robustness we also report results when the annual dummies are omitted and when the time varying controls are omitted. The fixed-effects models are estimated by Ordinary Least Squares and the random effects models by Maximum Likelihood, and in both cases we use cluster-robust covariance (Rogers, 1993) to account for potential correlations between error terms $\varepsilon_{i t}$ and $\varepsilon_{i t+s}$. The results are reported in Table 1 when we model the effect of investment in developed real estate, and in Table 2 where we consider undeveloped real estate investment. 
Table 1. Effect of Foreign Investment in Developed Real Estate on Residential Prices

\begin{tabular}{|l|l|l|l|l|l|l|}
\hline & \multicolumn{3}{|c|}{ Fixed Effects } & \multicolumn{3}{c|}{ Random Effects } \\
\hline Foreign Invest (D) & $4.59^{* * *}$ & 2.48 & $6.57^{*}$ & $4.16^{* *}$ & 1.87 & $4.84^{* * *}$ \\
\hline Unemployment & & $-4.05^{* * *}$ & $-3.90^{* *}$ & & $-3.43^{* * *}$ & $-3.19^{* *}$ \\
\hline Earnings & & -0.004 & 0.003 & & -0.02 & $-0.009^{*}$ \\
\hline Inflation & & $1.95^{* * *}$ & $4.76^{* * *}$ & & $2.18^{* * *}$ & $5.08^{* * *}$ \\
\hline Pop Growth & & $-1.8 \mathrm{E}-07$ & $-9.1 \mathrm{E}-06$ & & $9.4 \mathrm{E}-07$ & $-2.9 \mathrm{E}-07$ \\
\hline Y2005 & $3.72^{* *}$ & & $-9.39^{* * *}$ & $3.72^{* *}$ & & $-9.14^{* * *}$ \\
\hline Y2006 & $10.94^{* *}$ & & $-17.79^{* * *}$ & $10.96^{* *}$ & & $-18.04^{* * *}$ \\
\hline Y2007 & $19.57^{* * *}$ & & $-21.65^{* *}$ & $19.64^{* * *}$ & & $-21.70^{* *}$ \\
\hline Y2008 & $23.07^{* * *}$ & & $-37.21^{* *}$ & $23.18^{* * *}$ & & $-37.84^{* * *}$ \\
\hline Y2009 & $28.15^{* * *}$ & & $-34.67^{* *}$ & $28.18^{* * *}$ & & $-36.90^{* *}$ \\
\hline Y2010 & $37.83^{* * *}$ & & $-38.73^{* *}$ & $37.81^{* * *}$ & & $-41.26^{* *}$ \\
\hline Y2011 & $33.99^{* * *}$ & & $-58.01^{*}$ & $34.09^{* * *}$ & & $-60.56^{* * *}$ \\
\hline Y2012 & $33.96^{* * *}$ & & $-64.18^{* *}$ & $34.05^{* * *}$ & & $-67.11^{* * *}$ \\
\hline Y2013 & $38.09^{* *}$ & & $-69.39^{* *}$ & $38.26^{* * *}$ & & $-73.02^{* * *}$ \\
\hline Y2014 & $41.84^{* *}$ & & $-78.14^{* *}$ & $42.21^{* * *}$ & & $-82.01^{* * *}$ \\
\hline Constant & $65.22^{* * *}$ & $-66.38^{* *}$ & $-285.51^{* *}$ & $65.28^{* * *}$ & $-78.54^{* * *}$ & $-318.54^{* * *}$ \\
\hline$R^{2}$ & 0.893 & 0.897 & 0.952 & 0.894 & 0.896 & 0.950 \\
\hline$F / \chi^{2}$ & 53 & 131 & 87 & 568 & 643 & 1212 \\
\hline$\sigma_{u}$ & 3.41 & 5.63 & 5.76 & 3.12 & 4.17 & 4.31 \\
\hline$\sigma_{\varepsilon}$ & 5.68 & 5.36 & 3.91 & 5.68 & 5.36 & 3.91 \\
\hline Hausman $\chi^{2}$ & & & & 1.00 & 0.234 & 1.00 \\
\hline
\end{tabular}

Note: The first three columns give estimates from the fixed effects models using (i) only annual dummies, (ii) using only time varying economic conditions as controls, and (iii) using both annual dummies and time varying economic conditions as controls. The right three columns give the same estimates from the random effects models. The symbols *, ${ }^{* *}$ and $* * *$ denote significance at $1 \%, 5 \%$ and $10 \%$ respectively.

The results from Table 1 provide robust evidence for a strong linear association between foreign investment and Australian housing prices. The fixed-effects models in the first three columns estimate the effect of a billion dollar increase in investment as increasing the RPPI by between 2.5 and 6.57 units, assuming exogeneity and controlling variously for macroeconomic conditions including inflation. Of the three estimates, two are significantly different from zero at standard levels (effect sizes of 4.59 and 6.57) with the insignificant estimate occurring when the annual dummies are omitted. The random-effects models in the right columns give similar results with parameter estimates ranging between 1.87 and 4.84 RPPI units per current year billion dollar investment. Again the significant coefficients occur when the annual dummies are part of the model. Given that these dummies are generally highly significant we treat these as our preferred models and note that the estimates tend to cluster between 4 and 5 with a central value of around 4.5, which we treat as a stylized representative value. ${ }^{4}$

\footnotetext{
${ }^{4}$ This estimate corresponds to an elasticity of around 0.017 indicating that a $1 \%$ rise in proposed investment yields an increase in the price indices of $0.017 \%$ for a city with average investment and housing prices. For the
} 
Other diagnostic information from Table 1 indicates that the models perform well. In all cases the $R^{2}$ statistics are around $90 \%$ indicating that the models are capturing most of the variations in prices. As expected the models are all jointly significant with $F / \chi^{2}$ statistics exceeding standard thresholds in all cases. ${ }^{5}$ The terms $\sigma_{u}$ and $\sigma_{\varepsilon}$ give the standard deviations of the individual specific effects (fixed and random) and the time varying error terms across the models. We note that the degree of variation in these error terms is approximately equal which suggests that state-by-state heterogeneity absorbs about half of the variation in prices not accounted for by our time varying covariates. Turning to the control variables we observe that when significant, the estimated coefficients have the expected signs with unemployment suppressing the growth of housing prices and general price inflation having the reverse effect. This result serves as an informal specification test as unexpected coefficient signs can be an indicator of an incorrect functional form. Lastly the final row presents $\mathrm{p}$-values for Hausman-Wu (Wu, 1978; Hausman, 1978) tests of endogeneity in the random-effects models. These tests compare the coefficients from the fixed and random effects specifications under the assumption that the fixed effects model is consistent while the random effects model may or may not be. As these are greater than standard significance levels we conclude that there are no indications of biases in the randomeffects models relative to the fixed-effects specifications.

Table 2. Effect of Foreign Investment in Developing Real Estate on Residential Prices

\begin{tabular}{|l|l|l|l|l|l|l|}
\hline & \multicolumn{3}{|c|}{ Fixed Effects } & \multicolumn{3}{c|}{ Random Effects } \\
\hline Foreign Invest - FD & $1.18^{* * *}$ & 0.48 & $1.69^{* * *}$ & $1.03^{* * *}$ & 0.45 & $1.61^{* * *}$ \\
\hline Unemployment & & $-4.02^{* * *}$ & $-3.02^{*}$ & & $-3.50^{* * *}$ & $-2.44^{*}$ \\
\hline Earnings & & -0.01 & 0.005 & & $-0.02^{*}$ & -0.002 \\
\hline Inflation & & $1.97^{* * *}$ & $5.43^{* * *}$ & & $2.17^{* * *}$ & $5.66^{* * *}$ \\
\hline Pop Growth & & $2.8 \mathrm{E}-06$ & $-3.8 \mathrm{E}-06$ & & $9.6 \mathrm{E}-07$ & $-1.0 \mathrm{E}-06$ \\
\hline Y2005 & $4.55^{* *}$ & & $-9.41^{* * *}$ & $4.45^{* * *}$ & & $-9.26^{* * *}$ \\
\hline Y2006 & $12.10^{* *}$ & & $-19.36^{* * *}$ & $11.98^{* * *}$ & & $-19.55^{* * *}$ \\
\hline Y2007 & $21.30^{* * *}$ & & $-23.76^{* * *}$ & $21.17^{* * *}$ & & $-23.87^{* * *}$ \\
\hline Y2008 & $24.35^{* * *}$ & & $-42.58^{* * *}$ & $24.34^{* * *}$ & & $-43.09^{* * *}$ \\
\hline Y2009 & $29.47^{* * *}$ & & $-42.84^{* * *}$ & $29.35^{* * *}$ & & $-44.38^{* * *}$ \\
\hline Y2010 & $39.24^{* * *}$ & & $-48.48^{* * *}$ & $39.05^{* * *}$ & & $-50.08^{* * *}$ \\
\hline Y2011 & $35.11^{* * *}$ & & $-70.62^{* * *}$ & $35.10^{* * *}$ & & $-72.45^{* * *}$ \\
\hline Y2012 & $35.16^{* * *}$ & & $-78.45^{* * *}$ & $35.13^{* * *}$ & & $-80.56^{* * *}$ \\
\hline Y2013 & $40.69^{* * *}$ & & $-84.26^{* * *}$ & $40.59^{* * *}$ & & $-87.10^{* * *}$ \\
\hline Y2014 & $44.36^{* * *}$ & & $-95.13^{* * *}$ & $44.53^{* * *}$ & & $-98.46^{* * *}$ \\
\hline Constant & $63.51^{* * *}$ & $-72.51^{* * *}$ & $-357.39^{* * *}$ & $63.79^{* * *}$ & $-72.51^{* * *}$ & $-376.64^{* *}$ \\
\hline$R^{2}$ & 0.894 & 0.896 & 0.955 & 0.894 & 0.895 & 0.955 \\
\hline$F / \chi^{2}$ & 53 & 130 & 93 & 588 & 564 & 1401 \\
\hline$\sigma_{u}$ & 3.31 & 6.23 & 7.25 & 2.97 & 5.09 & 5.21 \\
\hline
\end{tabular}

sake of robustness we also report elasticities from log-linear and log-log models. Taking estimates using full sets of controls gives elasticities averaging around $0.019 \%$ and $0.058 \%$ respectively.

${ }^{5}$ The $F$ statistics are employed for the fixed effects models while the random effects models use $\chi^{2}$ statistics. 


\begin{tabular}{|l|l|l|l|l|l|l|}
\hline$\sigma_{\varepsilon}$ & 5.67 & 5.38 & 3.97 & 5.67 & 5.37 & 3.79 \\
\hline Hausman $\chi^{2}$ & & & & 1.00 & 0.616 & 0.996 \\
\hline
\end{tabular}

Note: The first three columns give estimates from the fixed effects models using (i) only annual dummies, (ii) using only time varying economic conditions as controls, and (iii) using both annual dummies and time varying economic conditions as controls. The right three columns give the same estimates from the random effects models. *, ** and *** denote significance at $1 \%, 5 \%$ and $10 \%$ respectively.

The results in Table 2 present a similar finding to those in Table 1. Proposed investment in property for development has a positive and significant effect on the RPPI in all models that control for year-specific effects. These estimates range from around 1 to 1.7 RPPI units per billion dollars of planned investment. Thus on a dollar-by-dollar basis property prices are around three times more sensitive to investment in developed real estate than in real estate for planned development. This result makes sense as it is likely that purchases of vacant land or land for redevelopment would have a much less direct effect on prices, and most likely operate at long lags due to the time taken to construct new dwellings. As with the models for developed real estate we wish to consider some diagnostics, and we observe that the equations for prospective development also perform well. Again the models are significant, the

$R^{2}$ terms are high and there are no signs of endogeneity in the random effects specifications. We also wish to generate a summary figure for the sensitivity of housing prices for this alternative measure of foreign investment. Since the models that contain both the annual dummies and the economic time-varying controls have the best chance of removing omitted variable bias we choose these as our preferred estimates. Thus the relevant slope coefficients are estimated to be between 1.61 and 1.69, and therefore we chose a midpoint of 1.65 units per billion dollars as a stylized benchmark for this marginal effect. ${ }^{6}$

\section{Dynamic Estimations}

In addition to these regression equations it is possible to consider models where our housing price indices are determined dynamically as a function of both their previous values and also current period covariates. Such a model would make sense if prices were subject to momentum or hysteresis effects, where values at one point in time were set relative to values observed in the recent past (e.g. Goodhart and Hoffman, 2008; Davis and Zhu, 2009). To account for this possibility we employ the dynamic panel estimator of Arellano and Bond $(1991)^{7}$. This is a Generalized Method of Moments (GMM) estimation approach for including lagged dependent variables in short panels. As coefficients on lagged dependent variables are biased in small samples an IV estimator based upon further lags is used to remove potential endogeneity problems and produce consistent estimates. The specification is

$$
y_{i t}=\alpha+\gamma_{t}+\mathbf{x}_{i t}^{\prime} \boldsymbol{\beta}+\rho_{1} y_{i t-1}+\rho_{2} y_{i t-2}+u_{i}+\varepsilon_{i t}
$$

As our models with annual dummies in Tables 1 and 2 were preferred we stick with these specifications but now add lagged vales of our dependent variables to control for these

\footnotetext{
${ }^{6}$ This translates into an elasticity of approximately $0.029 \%$ evaluated at the sample means. Averages over the fully specified log-linear and log-log models give elasticities of $0.029 \%$ and $0.020 \%$ respectively.

${ }^{7}$ Various techniques for estimating dynamic panels using GMM to correct for endogeneity have also been developed by Arellano and Bover (1995), and Blundell and Bond (1998) amongst others.
} 
potential dynamic effects. Across all our models we find that the use of two lags tends to provide the best results so this set of models is retained throughout. The estimates are presented in Table 3.

Table 3. Dynamic Models of Australian Residential Real Estate Prices

\begin{tabular}{|l|l|l|l|l|}
\hline & \multicolumn{2}{|c|}{ Developed } & \multicolumn{2}{c|}{ For Development } \\
\hline Lag 1 & $0.96^{* * *}$ & $0.80^{* * *}$ & $0.85^{* * *}$ & $0.72^{* * *}$ \\
\hline Lag 2 & $-0.40^{* * *}$ & $-0.36^{* * *}$ & $-0.34^{* * *}$ & $-0.33^{* * *}$ \\
\hline Foreign Investment & $3.41^{* * *}$ & $3.49^{* * *}$ & $1.13^{* * *}$ & $1.03^{* * *}$ \\
\hline Unemployment & & $-1.77^{* *}$ & & $-1.39^{*}$ \\
\hline Earnings & & 0.00 & & 0.00 \\
\hline Inflation & & 1.10 & & 1.41 \\
\hline Pop Growth & & $-1.5 \mathrm{E}-06$ & & $-4.2 \mathrm{E}-07$ \\
\hline Y2006 & -2.13 & 2.71 & -3.78 & 7.77 \\
\hline Y2007 & 1.07 & 3.80 & 0.40 & 9.20 \\
\hline Y2008 & -1.13 & -1.70 & -1.81 & 2.59 \\
\hline Y2009 & $3.52^{* *}$ & 4.04 & $2.93^{*}$ & 7.23 \\
\hline Y2010 & $10.57 * * *$ & 8.24 & $10.41^{* * *}$ & 11.03 \\
\hline Y2011 & $6.10^{* * *}$ & -4.33 & $5.38^{* * *}$ & -2.41 \\
\hline Y2012 & $9.43^{* * *}$ & 0.20 & $10.04^{* * *}$ & 0.86 \\
\hline Y2013 & $9.06^{* * *}$ & 2.26 & $9.63^{* * *}$ & 3.03 \\
\hline Constant & $37.98^{* * *}$ & -40.02 & $42.36^{* * *}$ & -73.16 \\
\hline Sargan (P) & 0.071 & 0.092 & 0.217 & 0.132 \\
\hline
\end{tabular}

Note: The first two columns give the dynamic models for developed real estate using (i) only annual dummies as time varying controls and (ii) using all available controls. The second two columns do the same for investment in property for development. Note that the use of lagged values requires the elimination of some annual dummies which become co-linear with the intercept. *, ** and ${ }^{* * *}$ denote significance at $1 \%, 5 \%$ and $10 \%$ respectively.

The dynamic models provide several additional insights into the behaviour of our price index. Firstly we see that over all models the two lagged terms are significant with the first term exhibiting a large positive sign and the second a smaller negative sign. The instrumental variables used to generate these estimates pass Sargan (1958) tests of overidentifying restrictions at $5 \%$ significance (but not $10 \%$ ) which suggests that the procedure is generally sound, although given our limited sample size we were not always able to set up our estimations such that the residuals were free of autocorrelation at the second lag. However given the constraints on our data and the fact that our autoregressive terms are only designed to act as controls we do not regard this problem as too severe.

In terms of interpretation of our lagged coefficients we do not place too strong an emphasis on either (i.e. the positive and negative signs) due to the strong collinearity between the lags, but rather note that taken together they imply moderately strong positive persistence in prices over time lasting a full two years. Once this effect is controlled for we can consider the roles of the investment variables while accounting for intertemporal persistence. As is typical in these models the effect sizes are smaller as variations in the dependent variable are partially 
explained by previous values, although in all cases the parameters are significant and of the expected sign. Foreign investment in developed real estate is associated with an effect of 3.43.5 RPPI units per billion, while for undeveloped real estate the slope coefficients range from 1.0-1.1.This translates into percentage increases of $0.013 \%$ and $0.017 \%$ respectively. Although these estimates imply a smaller effect size the findings add further robustness to our findings of a significant positive relationship existing between these variables.

\section{Simulated Changes in Housing Price Indices}

The results in Tables 1-3 indicate that, based on a variety of different models, prospective foreign investment in the domestic real estate market coincides with a positive and significant movement in Australian housing prices. However in order to fully interpret these results it is useful to consider how large the effect sizes we estimate really are. To accomplish this we take the RPPI scores from each city in 2004 and 2014 and consider how much of the rise that has been observed can be attributed to changes in foreign investment over this time span. This is done by taking the change in the index and subtracting out the change in foreign investment (corrected for inflation) multiplied by our stylized coefficients from the static models presented in Tables 1 and 2, and the dynamic models in Table 3. This is then standardized by the former difference to form a percentage for each major city and the results of which are presented in Table 4.

Table 4. Simulated Changes in Housing Price Growth Attributed to Foreign Investment

\begin{tabular}{|l|c|c|c|c|}
\hline & \multicolumn{2}{|c|}{ Static Models } & \multicolumn{2}{c|}{ Dynamic Models } \\
\hline City & Develop & For Dev & Develop & For Dev \\
\hline Sydney & $25.27 \%$ & $26.32 \%$ & $19.38 \%$ & $16.91 \%$ \\
\hline Melbourne & $29.78 \%$ & $29.69 \%$ & $22.83 \%$ & $19.07 \%$ \\
\hline Brisbane & $5.74 \%$ & $-17.90 \%$ & $4.40 \%$ & $-11.50 \%$ \\
\hline Adelaide & $3.08 \%$ & $0.17 \%$ & $2.36 \%$ & $0.11 \%$ \\
\hline Perth & $2.17 \%$ & $-7.74 \%$ & $1.66 \%$ & $-4.97 \%$ \\
\hline Hobart & $0.14 \%$ & $-0.05 \%$ & $0.11 \%$ & $-0.03 \%$ \\
\hline Darwin & $0.13 \%$ & $1.32 \%$ & $0.10 \%$ & $0.85 \%$ \\
\hline Canberra & $0.27 \%$ & $1.07 \%$ & $0.20 \%$ & $0.69 \%$ \\
\hline
\end{tabular}

Note: All estimates are calculated using $(\triangle R P P I-\triangle F I \times \beta) / \triangle R P P I$ where $\beta$ is the stylized summary estimate from Tables 1-3. These values are 4.5 and 3.45 for developed real estate and 1.65 and 1.05 for real estate marked for development.

The estimates in Table 4 give the proportion of price growth from 2004-2014 that is attributed via our parameter estimates to each type of foreign investment. Note that as our measures of foreign investment were modelled separately that figures should not be aggregated, rather they represent alternative estimates of the same underlying phenomena. The first two rows show that when the static (i.e. fixed or random effects) models were used, foreign investment growth accounted for between $25 \%$ and $30 \%$ of the increase in prices over this period in Sydney and Melbourne. This implies, subject to exogeneity assumptions, that 
our housing price index would have increased by only about 50\% from 2004-2014 rather than the observed $67 \%$ if foreign investment was held constant. When the dynamic models are employed the effects are smaller and suggest that foreign investment accounts for between $17 \%$ and $23 \%$ of the trend in prices in these cities. For the other major cities the results are more ambiguous as the levels of investment are much lower and in some cases are negative. In Brisbane the investment in developed real estate is found to account for about $5 \%$ of the price rise, while the reduction in investment in undeveloped real estate is credited with a reduction of almost 18\%. This last value is something of an outlier, but when combined with the other results we tend to see either small positive contributions typically of the order of 0$3 \%$ or small negative contributions of around the same size. This is what we would expect if the true combined effect size was around zero, and therefore for Australia's smaller capital cities it does not appear that either form of foreign investment has had a marked impact upon housing prices.

These results suggest that overall, foreign investment only plays a moderate role in Australia's property boom. This implies that other factors such as CPI inflation, changes in domestic demand and supply constraints are likely to account for much greater proportions of the trends that we have observed, especially in cities outside of Sydney and Melbourne which still saw large price increases but where such investment was relatively sparse.

\section{Conclusion}

Housing prices in Australian capital cities grew sharply from 2004 to 2014, a phenomenon which was particularly evident in Sydney and Melbourne. The econometric models we employ suggest that about one quarter of the growth in these two cities can be attributed to foreign investment. One way to conceptualize this result is that if foreign investment was held steady over the period, the housing price indices for Sydney and Melbourne would have grown by about $50 \%$ compared with actual growth of $67 \%$. In Brisbane, Adelaide and Perth the growth of proposed investment was much less and therefore the effects on prices were smaller. The general finding based upon a consensus of models is that foreign investment had a minimal association with housing prices in these smaller capital cities. This may well mask much larger effects in certain suburbs and in the higher price brackets, as reported anecdotally in the media. Verifying these reports would require more reliable and detailed data by locations within cities, and by price brackets. The Parliamentary Report on Foreign Investment in Residential Real Estate (Commonwealth of Australia, 2014) noted the Committee's frustration with the lack of data and recommended a national register of land title transfers that records the citizenship and residency status of all purchases of Australian real estate.

Apart from calling for more reliable data on foreign ownership of residential housing, the results here do not support knee-jerk policy responses in relation to foreign investment in real 
estate. There is considerably more to the rapid and substantial rise in housing prices in Sydney and Melbourne from 2010 to 2015 than can be explained by foreign investment. It is also worth noting that foreign investment in any Australian asset class, including housing, does not represent a wealth transfer to foreigners. If the public policy concern is more about housing affordability, then policies that aim to boost housing supply and that address tax and retirement income policies favouring housing over other asset classes would be more effective than a clamp-down on foreign real estate investment.

The Henry Tax Review (Henry, 2009) noted that the tax-preferred treatment of both owneroccupied and investment housing contribute to higher house prices; this includes negative gearing on investment properties and the capital gains tax exemption on owner-occupied housing. Taxation also has cost-push effects through taxes on development and construction such as GST, developer charges and stamp duty. The Henry Review recommended abolishing stamp duty on property transfers and reducing the dollar amount of negative gearing through discounting rental property losses that can be charged against other income. The exemption of owner-occupied housing from the pension assets test, combined with tapering of pension as the value of other assets increases, encourages retirees to switch assets into the family home in order to increase their pension. This is another factor contributing to housing demand and house price growth. The Henry Review recommended replacing the assets test with a comprehensive means test base that would include deemed income from owneroccupied housing that exceeds a threshold value. 


\section{References}

Arellano, M. and S. Bond. 1991. Some tests of specification for panel data: Monte Carlo evidence and an application to employment equations. Review of Economic Studies 58: 27797.

Arellano, M. and O. Bover. 1995. Another look at the instrumental variable estimation of error-components models. Journal of Econometrics 68: 29-51.

Blundell, R., and S. Bond. 1998. Initial conditions and moment restrictions in dynamic panel data models. Journal of Econometrics 87: 115-43.

Commonwealth of Australia. 2014. Report on foreign investment in residential real estate. House of Representatives Standing Committee on Economics. The Parliament of the Commonwealth of Australia.

Davis, E. and Zhu, H. (2009). "Commercial property prices and bank performance" Quarterly Review of Economics and Finance, 49, 1341-1359.

Federal Reserve Bank of Dallas (2016). "International House Price Database”, http://www.dallasfed.org/institute/houseprice/, accessed 6.11.16

Gauder, M., Houssard, C. and D. Orsmond. 2014. Foreign investment in residential real estate. Reserve Bank of Australia, Bulletin, June Quarter, 11-18.

Goodhart C., Hofmann B. (2008). 'House prices, money, credit, and the macroeconomy’ Oxford Review of Economic Policy, 24, 180-205.

Griliches, Z. (1984). “Data problems in econometrics” NBER Technical Working Papers 0039, National Bureau of Economic Research, Inc.

Hausman, J. (1978). “Specification Tests in Econometrics” Econometrica, 46, 1251-1271.

Henry, K. (2009) “Henry et al Australia’s Future Tax System: Report to the Treasurer”, December, Canberra.

Kohler, M. and M. van der Merwe (2015). Longer-run trends in housing price growth. Reserve Bank of Australia, Bulletin, September Quarter, 21-30.

Otto, G. (2007), 'The Growth Rate of House Prices in Australian Capital Cities: What do Economic Fundamentals Explain?’, Australian Economic Review, 40, 225-38 
Rogers, W. H. 1993. Regression standard errors in clustered samples. Stata Technical Bulletin 13: 19-23, vol. 3, 88-94.

Sargan, J. D. (1958). "The Estimation of Economic Relationships Using Instrumental Variables". Econometrica 26 (3): 393-415.

Sydney Morning Herald (2014). Chinese buyers fuelling Sydney property hotspot demand. January 29, 2014. http://www.smh.com.au/business/property/chinese-buyers-fuelling-sydneyproperty-hotspot-demand-20140129-31m1b.html

Wu, De-Min (July 1973). "Alternative Tests of Independence between Stochastic Regressors and Disturbances". Econometrica 41 (4): 733-750. 